\title{
Parents' Knowledge, Attitude, and Practice on Childhood Vaccination During the COVID-19 Pandemic in Indonesia
}

\author{
Rano K Sinuraya (iD ${ }^{1-3}$ \\ Arif SW Kusuma ${ }^{3,4}$ \\ Zinzi E Pardoel' \\ Maarten J Postma 1,3,5,6 \\ Auliya A Suwantika (D) 2,3,7 \\ 'Unit of Global Health, Department of \\ Health Sciences, University of Groningen/ \\ University Medical Center Groningen, \\ Groningen, the Netherlands; \\ ${ }^{2}$ Department of Pharmacology and \\ Clinical Pharmacy, Faculty of Pharmacy, \\ Universitas Padjadjaran, Bandung, West \\ Java, Indonesia; ${ }^{3}$ Center of Excellence in \\ Higher Education for Pharmaceutical \\ Care Innovation, Universitas Padjadjaran, \\ Bandung, West Java, Indonesia; \\ ${ }^{4}$ Department of Pharmaceutical Biology, \\ Faculty of Pharmacy, Universitas \\ Padjadjaran, Bandung, West Java, \\ Indonesia; ${ }^{5}$ Department of Economics, \\ Econometrics \& Finance, Faculty of \\ Economics \& Business, University of \\ Groningen, Groningen, the Netherlands; \\ ${ }^{6}$ Unit of Pharmacotherapy,-Epidemiology \\ \&-Economics, University of Groningen, \\ Department of Pharmacy, Groningen, the \\ Netherlands; ${ }^{7}$ Center for Health \\ Technology Assessment, Universitas \\ Padjadjaran, Bandung, West Java, \\ Indonesia
}

Background: Vaccination is known to have an enormous impact on improving child health. In Indonesia, the government has included several vaccines in the national immunization program.

Objective: This study aimed to investigate parents' knowledge, attitude, and practice on childhood immunization during the COVID-19 pandemic in Indonesia.

Methods: A valid and reliable questionnaire was delivered to approximately 276 parents in Jakarta and Bandung, representing the epicenter of the pandemic. This study was conducted from June 2020 to February 2021. The correlations between parents' knowledge, attitudes, and practice with the characteristics of the respondents were investigated. In addition, multiple regression analysis was performed to identify the variables associated with good vaccination practice.

Results: The results showed that the mean scores of parents' knowledge, attitude, and practice on childhood vaccinations were $7.22( \pm 1.30)$ out of 9 points, $3.93( \pm 0.31)$ out of 4 points, and 3.59 ( \pm 0.97) out of 5 points, respectively. Respondents graduated from university were more knowledgeable than those graduated from senior high school ( $p$-value $<0.05$ ). Employed participants had better scores in knowledge and practice, compared to unemployed participants ( $p$-value $<0.05$ ).

Conclusion: In conclusion, this study found positive correlations between participants' knowledge and attitude, knowledge and practice, and attitude and practice on childhood vaccination during the COVID-19 pandemic in Indonesia.

Keywords: KAP study, vaccine, immunization, childhood vaccination

\section{Introduction}

Although the Indonesian government has included regular vaccination for children in the National Immunization Program (NIP) and strongly supports its implementation, vaccination coverage remains lower than the targeted coverage of World Health Organization (WHO) and United Nations International Children's Emergency Fund (UNICEF). ${ }^{1}$ The results of Basic Health Research in 2018 reported rates of complete primary immunization, incomplete immunization, and non-immunization at $57.9 \%, 32.9 \%$, and $9.2 \%$, respectively. ${ }^{2}$ Shortfalling vaccination coverage was also reported in the NIP, where all vaccinations are free for children, such as Hepatitis B, diphtheria, pertussis, tetanus, tuberculosis, pneumonia, meningitis, polio, and measles vaccinations. ${ }^{1,3}$

As an archipelago country, the coverage of NIP in Indonesia was not distributed uniformly across the provinces, which might be caused by several factors, such as
Correspondence: Auliya A Suwantika Faculty of Pharmacy, Universitas Padjadjaran, Jl. Raya Bandung-Sumedang $\mathrm{Km}$. 2I, Jatinangor, Sumedang, 45363, Indonesia

Email auliya@unpad.ac.id 
socio-economic and demographic factors. ${ }^{4-6}$ In addition, a previous study reported that vaccination coverage was higher in urban areas than in rural areas. ${ }^{7}$ In rural areas, there are several risk factors for low coverage, such as the absence of healthcare facilities and potential lack of information on the importance of childhood vaccination. ${ }^{7,8}$ Despite the higher coverage in urban areas, the rates are still lower than the government's targets. ${ }^{2,9}$ Moreover, the coronavirus disease 2019 (COVID-19) pandemic was reported to have a significant impact on the performance of NIP in Indonesia, further threatening adequate coverage rates. ${ }^{10}$

By June 2021, the number of COVID-19 cases in Indonesia was reported to be 2.14 million, with the Delta variant accounting for $80 \%$ of cases. The coverage of COVID-19 vaccination was reported to be $64.54 \%$ and $42.84 \%$ for the first and second doses, respectively. ${ }^{11,12}$ There are some factors that may influence the slow progress of COVID-19 vaccination in Indonesia, such as vaccine hesitancy related to side effect of vaccine and vaccine manufacturer, anti-vaccine movement, and inadequate cold-chain system to deliver the vaccines. ${ }^{11,13,14}$ Several previous studies mentioned that willingness to vaccinate against COVID-19 was associated with the acceptance of COVID-19 vaccine itself. ${ }^{15,16}$ A similar situation may occur in Indonesia when COVID-19 vaccine is administered for 6-11 years old children in late 2021 or early 2022 .

To understand immunization coverage in children, knowledge, attitudes, and practice (KAP) studies are relevant to measure the societal perspective on decisions about childhood vaccination.${ }^{17}$ Previous studies in China and the UK showed parents' high acceptability of COVID-19 vaccinations for their children. ${ }^{18,19}$ In particular, parents' knowledge and attitude have been acknowledged as important factors influencing decision-making on childhood vaccination. ${ }^{17,20}$ Higher knowledge would lead to positive attitudes and practices. A previous study highlighted a strong correlation between the lack of parents' knowledge about vaccines and unsuccessful implementation of immunization programs. ${ }^{21}$ In addition, parents frequently have a considerable interest in health-related issues and proactively seek information. ${ }^{22,23}$ Since the implementation of immunization program tends to be more complicated and multi-dimensional, a KAP study is warranted on childhood immunization in Indonesia, specifically in the COVID-19 pandemic situation. Our study aimed to perform a KAP-study in the era of COVID-19 with its specific challenges in Indonesia. Insights from this study can be used as a basis for developing an effective strategy to educate the community regarding the benefits of vaccination. ${ }^{24}$

\section{Methods}

A cross-sectional study was applied by conducting a survey from June 2020 to February 2021 in Jakarta and Bandung, which represented the epicenter of the pandemic in Indonesia. Specifically, an online questionnaire was delivered to participants who met the major inclusion criteria of parents should have at least one child. A convenience sampling method was applied to select the participants, which were identified through virtual community engagement programs. The sample size for the cross-sectional survey was calculated by considering a conventional normal variate of type 1 error at $5 \%$, an anticipated proportion of participants at $50 \%$, and an absolute error at $10 \%$. The sample size was calculated to be 96 respondents. However, in this study we successfully recruited 276 respondents. The respondents were given an informed consent and a notification that the results of this voluntary study would be used for research purposes. This study was approved by the Health Research Ethics Committee of Universitas Padjadjaran, Indonesia (registration number: 1050/UN.6.KEP/EC/ 2020) and conducted in accordance with the Declaration of Helsinki.

A well-developed KAP questionnaire from a previous study was applied and translated into Indonesian. ${ }^{25} \mathrm{~A}$ link to fill in the survey was sent to the respondents through their email addresses. The questionnaire consisted of four parts, which covered the background of respondents, the assessment of knowledge (9 questions), attitude (4 questions), and practice (5 questions) (see Appendix). All questions about knowledge, attitude, and practice could be answered with yes/no. Validity and reliability tests were conducted accordingly. The respondents' responses were stored in a private online database. Correlations between parents' knowledge, attitudes and practice, and respondents' characteristics were investigated by using $t$-test. In particular, a pairwise Pearson's correlation coefficient was also taken into account. Finally, multiple regression analysis was conducted to identify variables that were correlated with good practice of vaccination. All analyses were conducted by using SPSS 27 (SPSS Inc., Chicago, IL, USA). 
A face validation was performed by two investigators (RK and AAS) and the reliability test was conducted in 30 respondents. The questionnaire resulted in Cronbach-alpha scores of $0.69,0.68$, and 0.66 for knowledge, attitude and practice, respectively, which were considered to be acceptable values. ${ }^{26,27}$ The coefficients of reproducibility and scalability were reported to be 0.91 and $0.81,0.97$ and 0.93 , and 0.92 and 0.84 , for knowledge, attitude, and practice, respectively. These values indicated that the questionnaire was valid and reliable, according to the Guttman requirement, which highlighted that the coefficients of reproducibility and scalability should be $\geq 0.9$ and $\geq 0.6$, respectively. ${ }^{28}$

Furthermore, the general characteristics were presented by taking descriptive statistics into account. The $t$-test was used to analyze the differences of knowledge, attitude and practice in each characteristic of participants. A pairwise Pearson's correlation coefficient was calculated by comparing participants' knowledge, attitude, and practice. A linear multiple regression analysis was also applied to identify factors influencing successful practice. In this analysis, nominal scales were transformed into dummy variables by using the codes of 0 and 1 , including gender $($ male $=1$, female $=0)$, age $(<38$ $=1, \geq 38=0$ ), education (university $=1$, senior high school $=0$ ), occupation (employed $=1$, unemployed $=0$ ), and having a child in kindergarten or primary school (yes $=1$, no $=0$ ). Furthermore, a DurbinWatson coefficient of 1.856 was used to indicate that there would not be autocorrelation. ${ }^{29}$ To confirm that there was no multicollinearity, we applied the tolerance level for all variables and the variation inflation factor (VIF) at $0.70-0.99$ and $1.02-1.42$, respectively. ${ }^{29,30}$ In addition, we applied a regression test that showed $p$-value at $<0.001$, the mean of the residual standard at 0 , and the range of the residual standard at below \pm 3 , which indicated no outlier. The regression model was assumed to be linear since the normality, residual, multicollinearity, regression test, and independent error met the required criteria.

\section{Results}

Out of 276 respondents who completed the questionnaire, the majority of respondents were female ( $82 \%)$, older than 38 years old (53\%), employed (54\%), graduated from university $(58 \%)$, and had children in kindergarten or primary school (67.4\%). More detailed information about the characteristics of participants can be seen in Table 1.
Table I Participants' Characteristics $(n=276)$

\begin{tabular}{|l|c|}
\hline Variable & n (\%) \\
\hline City & $111(40.2)$ \\
Jakarta & $165(58.8)$ \\
Bandung & \\
Gender & $50(18.1)$ \\
Male & $226(81.9)$ \\
Female & \\
Age (years old) & $130(47.1)$ \\
$<38$ & $146(52.9)$ \\
$\geq 38$ & \\
Education & $116(42.0)$ \\
Senior High School & $160(58.0)$ \\
University & \\
Occupation & $128(46.4)$ \\
Unemployed & $148(53.6)$ \\
Employed & $186(67.4)$ \\
Having a child in kindergarten or primary school & $90(32.6)$ \\
Yes & \\
No &
\end{tabular}

Considering several questions to investigate parents' knowledge about vaccination, it was found that the participants' level of knowledge at 7.22 (maximum of 9). One question that the majority of participants could not answer correctly was about convulsions and skin rash, which might result from vaccination (see Appendix). In response to a specific question about COVID-19 vaccine as a prevention strategy, only $70 \%$ of respondents could answer the question correctly, which was below the average score of all questions $(80 \%)$ (see Table 2).

To consider the participants' attitudes, we included four specific questions about the benefit of vaccination, vaccine safety, agreement on the NIP as a public program, and recommendations for friends and families to vaccinate their children, including the COVID-19 vaccine. The results showed that the average score on participants' attitudes toward childhood vaccination was 3.93 (maximum of 4), which indicated positive attitude. In the context of participants' practice, they were asked five other questions regarding the participation of their children in the previous NIP, their willingness to vaccinate their children with the new vaccine when it is available, their response if children have swelling because of vaccination, the use of pain relievers or analgesics to treat swelling, and their willingness to vaccinate their children during the pandemic situation. The results showed that the average score on participants' behaviour toward childhood 
Table 2 Participants' Knowledge About Vaccination

\begin{tabular}{|c|c|c|c|}
\hline Description of Items & Mean (SD) & Corrects Answer (\%) & Rank \\
\hline Is vaccination important for children from the first day of birth? & $0.99(0.10)$ & 98.9 & 1 \\
\hline Does vaccination prevent infectious disease? & $0.87(0.34)$ & 86.6 & 4 \\
\hline Could vaccination decrease the rates of mortality and disability? & $0.83(0.37)$ & 83.3 & 7 \\
\hline Could vaccination maintain child health? & $0.87(0.33)$ & 87.3 & 3 \\
\hline Could vaccination control diphtheria, tetanus, and pertussis? & $0.89(0.31)$ & 89.5 & 2 \\
\hline Could vaccination prevent coronavirus? & $0.70(0.46)$ & 69.6 & 8 \\
\hline Could childhood vaccines control measles? & $0.85(0.36)$ & 85.1 & 6 \\
\hline Are fever and pain associated with vaccines? & $0.87(0.34)$ & 87.0 & 5 \\
\hline Could convulsions and skin rush result from vaccination? & $0.35(0.48)$ & 34.8 & 9 \\
\hline TOTAL & $7.22(1.30)$ & 80.23 & \\
\hline
\end{tabular}

Table 3 Participants' Attitude and Practice Towards Vaccination

\begin{tabular}{|l|c|c|}
\hline Description of Items & $\begin{array}{c}\text { Mean } \\
\text { (SD) }\end{array}$ & Rank \\
\hline $\begin{array}{l}\text { Participants' attitude } \\
\text { Are vaccinations beneficial for your child? }\end{array}$ & $0.99(0.09)$ & 1 \\
$\begin{array}{l}\text { Are vaccinations safe for children? } \\
\text { Do you agree with the NIP as one of the }\end{array}$ & $0.99(0.10)$ & 2 \\
$\begin{array}{l}\text { Ministry of Health's programs? } \\
\text { Would you recommend friends and families to }\end{array}$ & $0.96(0.19)$ & 3 \\
$\begin{array}{l}\text { vaccinate their children, including COVID-19 } \\
\text { vaccine? }\end{array}$ & $3.93(0.31)$ & 4 \\
\hline TOTAL & $0.91(0.29)$ & 1 \\
\hline $\begin{array}{l}\text { Participants' practice } \\
\text { Did your child participate in the previous NIP? }\end{array}$ & $0.89(0.32)$ & 2 \\
$\begin{array}{l}\text { Apart from the vaccines that the government } \\
\text { requires, are you considering giving your child } \\
\text { other vaccines, such as pneumonia, diarrhea, } \\
\text { or COVID-19 vaccines, if they are available? } \\
\text { If your child has swelling due to vaccine, will } \\
\text { you apply cold compress? }\end{array}$ & $0.75(0.43)$ & 3 \\
$\begin{array}{l}\text { Would you use pain relievers (analgesics) to } \\
\text { treat swelling and pain after vaccination? } \\
\text { During the COVID-I9 pandemic, has your } \\
\text { child been vaccinated? }\end{array}$ & $0.68(0.47)$ & 4 \\
\hline TOTAL & $0.37(0.49)$ & 5 \\
\hline
\end{tabular}

vaccination was 3.59 (maximum of 4), which indicated good behavior (see Table 3 ).

Table 4 shows the differences of knowledge, attitude and practice in each characteristic of participants. The results showed that there were significant differences between respondents' education background and occupation with their knowledge. Specifically, respondents who graduated from university $(\mathrm{t}=-8.453, p$-value $<0.001)$ and employed respondents $(\mathrm{t}=5.052, p$-value $<0.001)$ have more knowledge on childhood vaccination. The study also found positive correlations between participants' knowledge and attitude $(r=0.241, p$-value $=0.000)$, knowledge and practice $(\mathrm{r}=0.216, p$-value $<0.001)$, and attitude and practice $(\mathrm{r}=0.249, p$-value $<0.001)$, as shown in Table 5 .

To identify variables that were correlated with good practice of vaccination, a linear multiple regression analysis was applied in this study. Considering seven variables (eg, gender, age, education, occupation, having a child in kindergarten or primary school, knowledge, and attitude), the explanatory power of these factors influencing good practice of childhood vaccination was calculated at $13.2 \%$ $(\mathrm{F}=6.570, p$-value $<0.001)$ (Table 6$).$ Furthermore, level of education $(\beta=0.161)$, occupation $(\beta=0.163)$, knowledge $(\beta=0.224)$, and attitude $(\beta=0.223)$ were considered to be the most influential variables in the good practice of childhood vaccination (see Table 6).

\section{Discussion}

This study aimed to assess parents' knowledge, attitudes and practices regarding childhood vaccination during the COVID-19 pandemic. It was found that the average knowledge score of the respondents in regard to childhood vaccination was good at $7.22 \pm 1.30$ with an overall correct rate of $80.23 \%$. This finding is similar with the results of two previous studies that were conducted in Saudi Arabia and North East Ethiopia, ${ }^{31,32}$ which confirmed that respondents have good knowledge of childhood vaccination, know the importance of giving complete vaccinations to their children, and understand that vaccination is not harmful. Another similarity from these studies is the results highlighted positive correlations between parents' level of education and occupational status with their knowledge. 
Table 4 Differences in Knowledge, Attitude, and Practice to Participants' Characteristics

\begin{tabular}{|c|c|c|c|c|c|c|}
\hline \multirow[t]{2}{*}{ Variables } & \multicolumn{2}{|c|}{ Knowledge } & \multicolumn{2}{|c|}{ Attitudes } & \multicolumn{2}{|c|}{ Practice } \\
\hline & Mean (SD) & $t(p)$ & Mean (SD) & $t(p)$ & Mean (SD) & $\mathbf{t}(\mathbf{p})$ \\
\hline \multicolumn{7}{|l|}{ Gender } \\
\hline Male & $7.38(1.23)$ & 0.953 & $3.96(0.19)$ & 0.630 & $3.42(0.810)$ & -1.412 \\
\hline Female & $7.19(1.32)$ & $(0.342)$ & $3.93(0.33)$ & $(0.529)$ & $3.63(0.994)$ & $(0.159)$ \\
\hline \multicolumn{7}{|l|}{ Age (years old) } \\
\hline$<38$ & $7.28(1.233)$ & 0.672 & $3.95(0.211)$ & 0.957 & $3.64(1.062)$ & 0.843 \\
\hline$\geq 38$ & $7.17(1.366)$ & $(0.502)$ & $3.92(0.38 \mathrm{I})$ & $(0.340)$ & $3.54(0.87 \mathrm{I})$ & $(0.400)$ \\
\hline \multicolumn{7}{|l|}{ Education } \\
\hline Senior High School & $6.53(1.146)$ & -8.453 & $3.94(0.239)$ & 0.220 & $3.65(0.978)$ & 0.893 \\
\hline University & $7.73(1.176)$ & $(<0.00 \mathrm{I})^{*}$ & $3.93(0.357)$ & $(0.826)$ & $3.55(0.956)$ & $(0.373)$ \\
\hline \multicolumn{7}{|l|}{ Occupation } \\
\hline Unemployed & $7.57(1.218)$ & 5.052 & $3.94(0.314)$ & 0.252 & $3.67(0.936)$ & 1.384 \\
\hline Employed & $6.81(1.284)$ & $(<0.00 \mathrm{I})^{*}$ & $3.93(0.3 \mid 2)$ & $(0.802)$ & $3.50(0.996)$ & $(0.167)$ \\
\hline \multirow{3}{*}{\multicolumn{7}{|c|}{$\begin{array}{l}\text { Having a child in } \\
\text { kindergarten or primary } \\
\text { school }\end{array}$}} \\
\hline & & & & & & \\
\hline & & & & & & \\
\hline Yes & $7.16(1.324)$ & $-1.193(0.234)$ & $3.92(0.359)$ & -1.181 (0.239) & $3.66(0.948)$ & $1.530(0.127)$ \\
\hline No & $7.36(1.257)$ & & $3.97(0.181)$ & & $3.47(1.024)$ & \\
\hline
\end{tabular}

Note: *Significant $\left(p^{<0.05)}\right.$.

Table 5 Correlations Between Participants' Knowledge, Attitudes, and Practice

\begin{tabular}{|l|c|c|}
\hline Variables & $\mathbf{r}$ & $\mathbf{p}$ \\
\hline Knowledge - Attitude & 0.241 & $<0.001$ \\
Knowledge - Practice & 0.216 & $<0.001$ \\
Attitude - Practice & 0.249 & $<0.001$ \\
\hline
\end{tabular}

Table 6 Variables Influencing Good Practice of Childhood Vaccination

\begin{tabular}{|c|c|c|c|c|c|}
\hline Variables & $\mathbf{B}^{\mathbf{a}}$ & SE & $\boldsymbol{\beta}$ & $\mathbf{t}$ & $\mathbf{p}$ \\
\hline Constant & -0.487 & 0.769 & & -0.633 & 0.527 \\
\hline Gender $^{\mathrm{b}}$ & -0.326 & 0.166 & -0.127 & -1.963 & 0.051 \\
\hline $\mathrm{Age}^{\mathrm{b}}$ & -0.001 & 0.006 & -0.008 & -0.125 & 0.900 \\
\hline Education $^{\mathrm{b}}$ & 0.307 & 0.126 & 0.161 & 2.425 & $0.016^{\circ}$ \\
\hline Occupation ${ }^{\mathrm{b}}$ & 0.309 & 0.128 & 0.163 & 2.408 & $0.017^{\circ}$ \\
\hline $\begin{array}{l}\text { Having child in } \\
\text { kindergarten or } \\
\text { primary school }^{\text {b }}\end{array}$ & 0.229 & 0.118 & 0.113 & 1.932 & 0.054 \\
\hline Knowledge & 0.163 & 0.050 & 0.224 & 3.232 & $0.001^{\circ}$ \\
\hline Attitude & 0.656 & 0.178 & 0.223 & 3.677 & $0.000^{\circ}$ \\
\hline
\end{tabular}

${ }^{a}$ Notes: ${ }^{a}$ Unstandardized coefficients. ${ }^{b}$ Dummy coding. ${ }^{c}$ Significant $(p<0.05)$.
Furthermore, factors that influence the good practice of parents participating in the childhood vaccination program were found to be level of education, occupation, level of knowledge and positive attitude towards vaccination.

Although the correct answers in the knowledge section were around $80 \%$, side effects of vaccination (eg, convulsions and skin rush) were particularly poorly understood. Participants might think the vaccine would be safe without side effects. This situation is similar with a previous KAP study in Oman, which confirmed that only $17 \%$ of participants knew information about side effect of vaccination. ${ }^{33}$ Furthermore, applying a maximum score of 9, participants' level of knowledge was reported to be 7.22. Although this level of knowledge is quite good, more detailed information for parents regarding the practice of vaccination during the pandemic remain important to keep the performance of childhood vaccination. An official guideline on childhood vaccination practice during the pandemic has been launched by the Ministry of Health (MoH), the Republic of Indonesia. However, only $78 \%$ of parents are aware of this guideline, according to the latest survey. ${ }^{34,35}$ This situation is relevant with the finding of three previous studies, which specifically 
highlighted that comprehensive information and guideline were still required by respondents who have positive attitudes towards childhood vaccinations. ${ }^{31,32,36}$

Regarding the section of parents' practice, the most favourable practice among all questions was highlighted in the participation of their children in the previous NIP. These findings are linear with the results of the latest Basic Health Survey in Indonesia and Health Profile of Bandung, which confirmed that the percentage of fully vaccinated children in Jakarta and Bandung was above $60 \%{ }^{2,37}$ The least favourable response was captured in parents' willingness to vaccinate their children under the pandemic situation. Several studies confirmed that even though parents have good knowledge and attitude towards getting vaccinations for their children, several factors influencing their willingness to vaccinate their children remain evident, such as waiting time at health-care facilities and insurance services. ${ }^{31,38}$ The COVID-19 pandemic might worsen this situation. Previously, the $\mathrm{MoH}$ confirmed that $84 \%$ of all health facilities reported immunization service interruption with observed bottlenecks at multiple levels. This situation was caused by the fear of contracting COVID-19. ${ }^{34,35}$

In particular, the results confirmed significant correlations between respondents' education background and occupation with respondents' knowledge. This situation is associated with the role of primary health centers in running a routine education program for parents about children's health. Cards were provided for parents to record their children's height, weight, health status, suggested nutrition, and vaccination regimen. ${ }^{39,40}$ Through this program, working parents with high education background can easily enhance their knowledge, specifically in childhood vaccination. This approach has proven to be effective in increasing the coverage of childhood vaccination. ${ }^{4,9}$ This result is also similar to the results of an earlier study in Pakistan, which suggested that working parents (adjusted OR 0.59, 95\% CI $0.37-0.94$; $p$-value $=0.02$ ) and parents with high education background (adjusted OR 0.21, 95\% CI $0.08-0.50 ; p$-value $\leq 0.001$ ) were less likely to reject vaccination of their children. ${ }^{41}$ This study also found positive correlations ( $p$-value $<0.001$ ) between participants' knowledge-attitude, knowledge-practice, and attitude-practice. This finding strengthened the results of a previous KAP study in Lebanon, which confirmed better knowledge was significantly associated with better attitude, while better knowledge and attitude were significantly associated with better practice. $^{38}$

In Indonesia, immunization services in the NIP are provided free of charge in public healthcare facilities. Before the pandemic, approximately $90 \%$ of children were vaccinated in public facilities. Since the first COVID-19 case was reported in March 2020, routine immunization coverage has been declining. ${ }^{10,34,35}$ Parents expressed concerns about the closure of immunization services in public healthcare facilities. This study found that level of education, occupation, knowledge, and attitude were considered the most influential variables in the good practice of childhood vaccination. In order to improve the practice of childhood vaccination in Indonesia, an effective strategy needs to be developed by taking those critical variables into account. In order to ensure good quality immunization services during the pandemic, an integrated reporting system and a strong collaboration between all stakeholders, such as central and local government need to be optimized to keep the performance of routine immunization programs.

Although this study has several major findings, several limitations were also identified. The first limitation is that the participants did not adequately represent the Indonesian population as this study focusedd in Jakarta and Bandung. The second limitation concerns potential lack of memory as to whether or not the respondents' children were fully vaccinated. This study can assist the stakeholders in making a decision regarding efforts to improve the practice of childhood vaccination in Indonesia, specifically during the pandemic situation.

\section{Conclusion}

This study found positive correlations ( $p$-value $<0.001$ ) between the participants' knowledge-attitude, knowledgepractice, and attitude-practice on childhood vaccination during the COVID-19 pandemic in Indonesia.

\section{Funding}

This study was funded by Universitas Padjadjaran (Grant number: 1959/UN6.3.1/PT.00/2021).

\section{Disclosure}

Professor Maarten J Postma reports grants, personal fees from various pharma companies, outside the submitted work. The authors have no other conflicts of interest to declare. 


\section{References}

1. WHO. Factsheet 2019 Indonesia: expanded Programme on Immunization (EPI); 2019. Available from: https://www.who.int/ docs/default-source/searo/indonesia/indonesia-epi-factsheet-2019. pdf?sfvrsn=9ca1cf18_2. Accessed December 30, 2021.

2. Ministry of Health Republic of Indonesia. Basic Health Research. Jakarta: Badan Penelitian dan Pengembangan Kesehatan, Kementerian Kesehatan Republik Indonesia; 2018.

3. Herliana P, Douiri A. Determinants of immunisation coverage of children aged 12-59 months in Indonesia: a cross-sectional study. BMJ Open. 2017;7(12):e015790. doi:10.1136/bmjopen-2016-015790

4. Holipah MA, Kuroda Y. Determinants of immunization status among 12- to 23-month-old children in Indonesia (2008-2013): a multilevel analysis. BMC Public Health. 2018;18(1):288. doi:10.1186/s12889018-5193-3

5. Gupta A Islands, inequalities and immunisation - Indonesia prepares for one of the world's largest vaccine campaigns; 2020. Available from: https://www.gavi.org/islands-inequalities-and-immunisationindonesia. Accessed December 30, 2021.

6. Bocquier A, Ward J, Raude J, Peretti-Watel P, Verger P. Socioeconomic differences in childhood vaccination in developed countries: a systematic review of quantitative studies. Expert Rev Vaccines. 2017;16(11):1107-1118. doi:10.1080/14760584.2017.138 1020

7. Hardhantyo M, Chuang Y-C. Urban-rural differences in factors associated with incomplete basic immunization among children in Indonesia: a nationwide multilevel study. Pediatr Neonatol. 2021;62 (1):80-89. doi:10.1016/j.pedneo.2020.09.004

8. Arat A, Burström B, Östberg V, Hjern A. Social inequities in vaccination coverage among infants and pre-school children in Europe and Australia - a systematic review. BMC Public Health. 2019;19(1):290. doi:10.1186/s12889-019-6597-4

9. Ministry of Health Republic of Indonesia. Comprehensive Multi Year Plan National Immunization Program Indonesia; 2010. Available from: https:/extranet.who.int/countryplanningcycles/sites/default/ files/country_docs/Indonesia/indonesian_cmyp_2010-2014.pdf. Accessed December 30, 2021.

10. Suwantika AA, Boersma C, Postma MJ. The potential impact of COVID-19 pandemic on the immunization performance in Indonesia. Expert Rev Vaccines. 2020;19(8):687-690. doi:10.1080/ 14760584.2020.1800461

11. Nugraha RR, Miranda AV, Ahmadi A, Lucero-Prisno DE. Accelerating Indonesian COVID-19 vaccination rollout: a critical task amid the second wave. Trop Med Health. 2021;49(1):76. doi:10.1186/s41182-021-00367-3

12. National COVID-19 vaccination [Internet]. Ministry of Health of Indonesia; 2021. Available from: https://vaksin.kemkes.go.id/\#/vac cines. Accessed December 30, 2021.

13. Pronyk P, Sugihantono A, Sitohang V, et al. Vaccine hesitancy in Indonesia. Lancet Planetary Health. 2019;3(3):e114-e5. doi:10.1016/ S2542-5196(18)30287-0

14. Triwardani R. Indonesian officials and media fight vaccine hesitancy, misinformation. Asian Pol Policy. 2021;13(4):635-639. doi:10.1111/ aspp. 12608

15. Rieger M. Willingness to vaccinate against COVID-19 might be systematically underestimated. Asian J Social Health Behav. 2021;4 (2):81-83. doi:10.4103/shb.shb_7_21

16. Kukreti S, Lu M-Y, Lin Y-H, et al. Willingness of Taiwan's Healthcare Workers and outpatients to vaccinate against COVID-19 during a period without community outbreaks. Vaccines. 2021;9 (3):246. doi:10.3390/vaccines 9030246
17. Riccò M, Vezzosi L, Gualerzi G, Signorelli C. Knowledge, attitudes and practices (KAP) towards vaccinations in the school settings: an explorative survey. $J$ Prev Med Hyg. 2017;58(4):E266-E78. doi:10.15167/2421-4248/jpmh2017.58.4.673

18. Zhang KC, Fang Y, Cao H, et al. Parental acceptability of COVID-19 vaccination for children under the age of 18 years: cross-sectional online survey. JMIR Ped Parenting. 2020;3(2):e24827-e. doi:10.21 96/24827

19. Bell S, Clarke R, Mounier-Jack S, Walker JL, Paterson P. Parents' and guardians' views on the acceptability of a future COVID-19 vaccine: a multi-methods study in England. Vaccine. 2020;38 (49):7789-7798. doi:10.1016/j.vaccine.2020.10.027

20. Filia A, Bella A, D'Ancona F, et al. Childhood vaccinations: knowledge, attitudes and practices of paediatricians and factors associated with their confidence in addressing parental concerns, Italy, 2016. Euro Surveill. 2019;24(6):1800275. doi:10.2807/1560-7917.ES.20 19.24.6.1800275

21. Qutaiba B, Al-lela O, Bahari MB, et al. Are parents' knowledge and practice regarding immunization related to pediatrics' immunization compliance? A mixed method study. BMC Pediatr. 2014;14(1):20. doi:10.1186/1471-2431-14-20

22. Dubé E, Gagnon D, Nickels E, Jeram S, Schuster M. Mapping vaccine hesitancy-country-specific characteristics of a global phenomenon. Vaccine. 2014;32(49):6649-6654. doi:10.1016/j.vaccine.20 14.09.039

23. McKee C, Bohannon K. Exploring the reasons behind parental refusal of vaccines. J Pediatr Pharmacol Ther. 2016;21(2):104-109. doi:10.5863/1551-6776-21.2.104

24. Abdullahi LH, Kagina BM, Cassidy T, Adebayo EF, Wiysonge CS, Hussey GD. Knowledge, attitudes and practices on adolescent vaccination among adolescents, parents and teachers in Africa: a systematic review. Vaccine. 2016;34(34):3950-3960. doi:10.1016/ j.vaccine.2016.06.023

25. Habib RF, Alsubhi RA, Saadawi DW, et al. Assessment of knowledge, attitude and practice of parents towards immunization of children in Saudi Arabia. Egypt J Hosp Med. 2018;71(2):2585-2589. doi: $10.12816 / 0045660$

26. Mohamad MM, Sulaiman NL, Sern LC, Salleh KM. Measuring the validity and reliability of research instruments. Procedia Social Behav Sci. 2015;204:164-171. doi:10.1016/j.sbspro.2015.08.129

27. Ursachi G, Horodnic IA, Zait A. How reliable are measurement scales? External factors with indirect influence on reliability estimators. Procedia Econ Finance. 2015;20:679-686. doi:10.1016/ S2212-5671(15)00123-9

28. Gothwal VK, Wright TA, Lamoureux EL, Pesudovs K. Guttman scale analysis of the distance vision scale. Invest Ophthalmol Vis Sci. 2009;50(9):4496-4501. doi:10.1167/iovs.08-3330

29. Tabachnick BG, Fidell LS. Using Multivariate Statistics 7th ed. Upper Saddle River, NJ: Pearson; 2018.

30. Johnston R, Jones K, Manley D. Confounding and collinearity in regression analysis: a cautionary tale and an alternative procedure, illustrated by studies of British voting behaviour. Qual Quant. 2018;52(4):1957-1976. doi:10.1007/s11135-017-0584-6

31. GebreEyesus FA, Tarekegn TT, Amlak BT, et al. Knowledge, attitude, and practices of parents about immunization of infants and its associated factors in Wadla Woreda, North East Ethiopia, 2019. Ped Health Med Ther. 2021;12:223-238. doi:10.2147/ PHMT.S295378

32. Almutairi WM, Alsharif F, Khamis F, et al. Assessment of mothers' knowledge, attitudes, and practices regarding childhood vaccination during the first five years of life in Saudi Arabia. Nursing Rep. 2021;11(3):506-516. doi:10.3390/nursrep11030047 
33. Al-Marshoudi S, Al-Balushi H, Al-Wahaibi A, et al. Knowledge, Attitudes, and Practices (KAP) toward the COVID-19 vaccine in Oman: a pre-campaign cross-sectional study. Vaccines. 2021;9 (6):602. doi:10.3390/vaccines 9060602

34. UNICEF. Indonesia: more than half of health facilities report significant disruptions to immunization services from COVID-19; 2020. Available from: https://www.unicef.org/indonesia/ press-releases/more-than-half-of-health-facilities-report-significantdisruptions-to-immunization-services. Accessed December 30, 2021.

35. Ministry of Health of Indonesia and UNICEF. Routine Immunization for Children during the COVID-19 Pandemic in Indonesia: perceptions of Parents and Caregivers; 2020. Available from: https:// covid19.go.id/storage/app/media/Materi\%20Edukasi/2020/ September/community-perception-survey-en-01-09-2020.pdf. Accessed December 30, 2021.

36. Burton-Jeangros C, Golay M, Sudre P. [Compliance and resistance to child vaccination: a study among Swiss mothers]. Rev Epidemiol Sante Publique. 2005;53(4):341-350. French. doi:10.1016/S03987620(05)84616-4

37. Bandung District Health Office. Bandung Health Profile. Bandung: Bandung District Health Office; 2019.
38. Matta P, El Mouallem R, Akel M, Hallit S, Fadous Khalife M-C. Parents' knowledge, attitude and practice towards children's vaccination in Lebanon: role of the parent-physician communication. BMC Public Health. 2020;20(1):1439. doi:10.1186/s12889-020-09526-3

39. Syiroj ATR, Pardosi JF, Heywood AE. Exploring parents' reasons for incomplete childhood immunisation in Indonesia. Vaccine. 2019;37 (43):6486-6493. doi:10.1016/j.vaccine.2019.08.081

40. Harjaningrum AT, Kartasasmita C, Orne-Gliemann J, Jutand M-A, Goujon N, Koeck J-L. A qualitative study on knowledge, perceptions, and attitudes of mothers and health care providers toward pneumococcal conjugate vaccine in Bandung, West Java, Indonesia. Vaccine. 2013;31(11):1516-1522. doi:10.1016/j.vaccine.2013.01.007

41. Khattak FA, Rehman K, Shahzad M, et al. Prevalence of Parental refusal rate and its associated factors in routine immunization by using WHO vaccine hesitancy tool: a cross sectional study at district Bannu, KP, Pakistan. Int J Infect Dis. 2021;104:117-124. doi:10. 1016/j.ijid.2020.12.029
Patient Preference and Adherence

\section{Publish your work in this journal}

Patient Preference and Adherence is an international, peer-reviewed, open access journal that focusing on the growing importance of patient preference and adherence throughout the therapeutic continuum. Patient satisfaction, acceptability, quality of life, compliance, persistence and their role in developing new therapeutic modalities and compounds to optimize clinical outcomes for existing disease

\section{Dovepress}

states are major areas of interest for the journal. This journal has been accepted for indexing on PubMed Central. The manuscript management system is completely online and includes a very quick and fair peer-review system, which is all easy to use. Visit http:// www.dovepress.com/testimonials.php to read real quotes from published authors. 